\title{
BRASIL SEM HOMOFOBIA : reflexões e apontamentos sobre a diversidade sexual
}

\section{Alcilene Lopes de Amorim Andrade}

Psicóloga, pós graduada em Psicologia Clínica, Mestre em Educação, Professora de Psicologia Jurídica FUPACTO - E-maiL: alcileneaguia@hotmail.com

Camile Sibiem

Acadêmica do segundo período do curso de Direito da Faculdade Presidente Antônio Carlos de Teófilo Otoni - MG.

\section{Jussara Aparecida de Miranda}

Acadêmica do segundo período do curso de Direito da Faculdade Presidente Antônio Carlos de Teófilo Otoni - MG.

\section{Milena Santos Tigre}

Acadêmica do segundo período do curso de Direito da Faculdade Presidente Antônio Carlos de Teófilo Otoni - MG.

\section{Resumo}

Buscando consolidar direitos políticos, sociais e legais no enfretamento à homofobia, em 2004, o Governo Federal lançou o Programa de Combate à Violência e a Discriminação contra LGBT e Promoção da Cidadania Homossexual, conhecido como Brasil Sem Homofobia. Realizado por meio de pesquisa bibliográfica de cunho descritivo e delineamento qualitativo, este trabalho objetiva apresentar o conteúdo do polêmico "Kit Gay", como ficou pejorativamente conhecido, ressaltando a proposta do MEC no que tange 0 combate à homofobia nas escolas. A literatura revela que o plano de implementação proposto pelo programa Brasil Sem Homofobia recomendava em seu componente a promoção do respeito à paz e a não discriminação por orientação sexual. Em 2011 estava pronto para ser impresso, mas em virtude da campanha contra o projeto, realizada por pessoas que julgavam haver conteúdos que estimulariam o homossexualismo e a promiscuidade, foi suspenso.

Palavras chaves: Ideologia de Gênero, Diversidade sexual, Homofobia, Cidadania.

\section{Abstract}

In 2004, the Federal Government launched the Program to Combat Violence and Discrimination against LGBT and the Promotion of Homosexual 
Citizenship, known as Brazil Without Homophobia, seeking to consolidate political, social and legal rights in the fight against Homophobia. Conducted through a descriptive Bibliographic research and qualitative design, this work constitutes a content of the controversial "Gay Kit", as it was mainly knwn, highlighting the MEC proposal on the fight against homophobia in schools. The literate reveals that the implementation planned by Brazil without homophobia program is recommended in its component the promotion of respect for peace and non-discrimination based on sexual orientation. In 2011 it was ready to be printed, but by virtue of the campaign against the project, made by people whot hought there were contents that would stimulate homosexuality and promiscuity, it wassuspended.

Keywords: Genderideology, Sexual diversity, Homophobia, Citizenship

\section{Introdução}

A equipe do Projeto Escola Sem Homofobia elaborou os materiais educativos do kit,considerando o fato de que não basta apenas obter informações sobre o respeito à diversidade sexual e sobre como acabar com a homofobia, a lesbofobia e a transfobia, para que de imediato as pessoas abandonem possíveis atitudes homofóbicas, lesbofóbicas e transfóbicas.

Os materiais que compõem o kit educativo do projeto, buscavam contribuir para a desconstrução de imagens não verdadeiras sobre lésbicas, gays, bissexuais, travestis e transexuais, e promover como ganho a convivência e o respeito, às diferenças.

O "Kit Gay" como foi referido, é um caderno em que há ferramentas educacionais que compõem a base teórica e material com o qualse pretendia dar o passo inicial para a promoção e cidadania de uma escola livre de homofobia. Entretanto tornou-se centro de grande polêmica.

Assim sendo, esse artigo objetiva, por meio revisão de literatura e em especial, análise ao Caderno Brasil Sem Homofobia,apresentar o conteúdo do" Kit Gay" como foi pejorativamente conhecido, ressaltando a proposta do MEC no que tange ao combate à homofobia nas escolas. Para tanto, desenvolveu-se pesquisa bibliográfica, de cunho descritivo e delineamento qualitativo.

\section{Homofobia e a diferença entre informar e conhecer}

Segundo Edgar Morin (2001, p.36), "é preciso situar as informações e os dados em seu contexto para que adquira sentido". Por exemplo, "[...] a palavra 
amor muda de sentido no contexto religioso e no contexto profano, e uma declaração de amor não tem o mesmo sentido de verdade se é enunciada por um sedutor ou por um seduzido".

Depreende-se então, que a transformação da informação em conhecimento articulação com o cotidiano, com as práticas culturais, com a realidade e a visão de mundo dos sujeitosde modo que tenha significado, promove segurança para estruturar, organizar, reorganizar, construir ou reconstruir a percepção da realidade, de acordo com a cultura na qual se está inserido.

Para Brandão e Santana (2011, p.170):

Homofobia pode ser definida como uma série de atitudes de cunho
negativo, como repulsa ou exclusão, aos "homoeróticos" ou a
"homoafetivos". A palavra preconceito citada remete à conceituação
de Cultura - de acordo com Roberto DaMatta (1981), pesquisador e
professor de Antropologia Social do Museu Nacional da Quinta da
Boa Vista - a Cultura pode ser definida como "(...) a maneira de viver
total de um grupo, sociedade, país ou pessoa."; logo, uma criança
quando nasce, desperta já inserida num grupo social com
determinados conceitos pré-estabelecidos. Desta forma, o termo
preconceito pode ser definido como um conjunto de conceitos pré-
existentes já convencionados ao nascimento do ser humano. Ao
crescer em meio à discriminação à "homoafetividade" e
"homoeroticidade", ela possuirá o pré-conceito condizente com a
realidade na qual ela foi criada, repudiando as diferenças de
"preferência" sexual, podendo apresentar atitudes que vão do
desprezo á violência contra "homoafetivos" e "homoeróticos". O
programa do governo Brasileiro de combate a homofobia, portanto,
pretende alterar estes pré-conceitos gradativamente por meio de
medidas que mostrarão o quão errado é uma atitude discriminatória
deste gênero

Nesse sentido, apresentam-se a seguir aspectos importantes do material, objeto desta análise.

\section{3."Kit Escola Sem Homofobia" : o que seria esse caderno?}

A proposta do caderno Escola Sem Homofobia seria um convite às (aos) educadoras (es) para um debate, disponibilizando instrumentos pedagógicos para reflexão, compreensão e enfrentamento da homofobia no ambiente escolar.

A importância de construir e partilhar conhecimentos estão evidenciados neste caderno, organizado em capítulos que trazem situações 
problematizadoras relacionadas a seus eixos temáticos e propostas de dinâmicas para a discussão dos conceitos e temas, visando subsidiar práticas pedagógicas com um sentido reflexivo e de incentivo a mudanças. Essas dinâmicas podem ser aplicadas à comunidade escolar e, em especial, a estudantes do ensino médio.(BRASIL, 2015)

O caderno apresenta uma proposta conceitual e metodológica visando oferecer instrumentos pedagógicos para abordar temáticas relativas à orientação sexual e a identidades de gênero, trazendo a homofobia como uma questão central a ser problematizada nas escolas.

\subsection{Objetivos e Metodologia}

Tem intuito de alterar concepções didáticas, pedagógicas e curriculares, rotinas escolares e formas de convívio social que funcionem para manter fronteiras rígidas entre a sexualidade e entre os gêneros que reproduzem a homofobia no ambiente escolar. A ideia seriafazer com que se percebam as situações em que essas fronteiras são demarcadas e a homofobia é reproduzida; e se aprendam com elas com visando novas formas de argumentação, mobilizando e multiplicando práticas e linguagens que abram possibilidades de contribuir com a construção de práticas pedagógicas e institucionais que valorizem positivamente a diversidade sexual.(BRASIL, 2015)

Ressalta-se que caso as práticas curriculares continuem a reproduzir divisões e diferenças, situações de opressões de determinados grupos, mesmo aqueles e aquelas que se consolidam membros dos grupos privilegiados acabam sofrendo. Portanto, faz-se necessário alertar para aconstrução de um trabalho de respeito às diferenças e aos diferentes modos de ser e estar no mundo, incentivando debates, uma vez que a escola é um espaçointersubjetivo.

Conforme conteúdos do caderno elaborado pelo Projeto Brasil Sem Homofobia, (2004), o Kit Gay busca revelar a ordem que evidencia a heteronormatividade, como única possibilidade dos sujeitos viverem suas sexualidades, utilizandodinâmica de trabalho com as quais se pretendia subsidiar práticas pedagógicas que contribuíssem na promoção de mudanças.

O caderno que compõe o "Kit" possui em sua organização subtemas: 
a) Uma situação disparadora - que estimula o debate proposto para o capítulo;

b) Texto - desenvolvimento do eixo temático a ser discutido, trazendo conceitos, considerações críticas e subsídios de pesquisas e estudos, incluindo situações que podem ocorrer no cotidiano da escola e que nos desafiam a enfrentar a homofobia;

c) Dinâmicas: como fazer? - ações, passos ou procedimentos necessários para a organização de atividades práticas sugeridas, tendo como objetivo exercitar a capacidade reflexiva das/dos participantes;

d) Comentários finais - elencando alguns pontos de reflexão que visão sistematizar o conteúdo discutido. (BRASIL, 2015, p.20)

As dinâmicas incluídas no caderno, segundo autores do Kit (2004), funcionam como sugestões de atividades que poderão ser realizadas com os profissionais que trabalham na escola; estudantes na sala de aula; familiares; e com a comunidade no entorno da escola. Salienta-se que os debates detonados por essas dinâmicas estão impregnados das relações afetivas e de convivência que em nenhuma hipótese podem ser desconsiderados pela escola como conteúdos importantes a serem trabalhados, entre eles a cooperação, a solidariedade, o trabalho em grupo, o respeito e a ética.

Do material, objeto de estudo neste texto, conta ainda com os boletins Escola Sem Homofobia (boleshs) e três audiovisuais, compondo o Kit, objetivandocontribuir para provocar o debate e fundamentar o tema central do Projeto Brasil Sem Homofobia.

\subsection{0 primeiro capítulo - "Desfazendo a confusão"}

Aborda o conceito de gênero e a maneira como os conteúdos das diversas disciplinas escolares transmitem os modos de pensar, sentir e agir considerados apropriados ao sexo masculino, em contraposição àqueles vistos como adequados ao sexo feminino. Considerando a necessidade de discutirconceitos básicos para entender a diversidade sexual, esclarece dúvida do senso comum e desconstrói conceitos equivocados a respeito de identidade gênero e orientação sexual.

Neste ponto, o material produzido destaca a homofobia na escola, ressaltando a necessidade de se observarem atentamente informações e conhecimentos adquiridos no cotidiano escolar e nos livros didáticos, e a importância de falar do assunto como forma de enfrentar o preconceito e a discriminação contra a mulher e as/os LGBTs.Enfatiza ainda, a história dos movimentos, das conquistas e dos desafios das/os LGBTs por sua cidadania, 
no Brasil e em outros países, mostrando a importância da inserção desse grupo nos planos das políticas nas várias áreas e níveis, entre os quais a escola.(CONSELHO NACIONAL DE COMBATE À DISCRIMINAÇÃO, 2004)

\subsection{Segundo capítulo -"Retratos da homofobia na escola"}

A proposta é desconstruir a homofobia no cotidiano escolar, explorando conceitos que possibilitem discutir e compreender as particularidades dos estereótipos criados em torno de gays, lésbicas, bissexuais, transexuais e travestis, demonstrando como o silêncio diante de manifestação homofóbica pode conduzir a agressões e violência de todo tipo.(VIANNA; RAMIRES,2008)

O texto apresenta dados que apontama existência de uma cultura homofóbica nas escolas. Ressalta-senessa parte, a relevância de discutirpráticas escolares que dissimulam conceitos dogmáticos e naturalizados sobre orientação sexual, seja por meio da linguagem utilizada no cotidiano do ambiente ou da forma com a qual os conhecimentos são oferecidos nos livros didáticos e nas disciplinas ou matérias curriculares, bem como na organização do espaço escolar.

Pontuam-se os mecanismos legais, importantes para a luta contra a discriminação, dentre os quais a Declaração Universal dos Direitos Humanos , que defende que todos os seres humanos têm direitos iguais, sem distinção alguma de raça, cor, sexo, língua, religião, opinião política ou outra, de origem nacional ou social, de fortuna, nascimento ou qualquer outra situação. A Constituição Federal de 1988, que tem como objetivo assegurar o exercício dos direitos sociais e individuais - tais como a liberdade, a igualdade, a justiça entre outros - concebidos como valores supremos de uma sociedade fraterna, pluralista, e sem preconceito.

No Artigo $3^{\circ}$, inciso IV, CF consta que "promover o bem de todos, sem preconceitos de origem, raça, sexo, cor, idade e quaisquer outras formas de discriminação." (BRASIL, 1988) . E o Estatuto da Criança e Adolescente (ECA) em seu artigo $17^{\circ}$ afirma "o direito ao respeito consiste na inviolabilidade da integridade física, psíquica e moral da criança e do adolescente, abrangendo a preservação da imagem, da identidade, da autonomia, dos valores, ideias e crenças, dos espaços e objetos pessoais.(BRASIL, 1990) 
No entanto, cumpre ressaltar que estes princípios, visando a garantia de direitos, só efetivarão mediante a promoção dos valores que passam pela educação. Pode-se afirmar que o Brasil tem buscado o enfrentamento, via educação, de todas as formas de discriminação atentando para anecessidade de honrar o compromisso de educar para a diversidade; que para além de apenas reconhecer as diferenças, implica refletir sobre as relações e os direitos de todas as pessoas. Sendo a escola um território privilegiado de construção de conhecimento e de desenvolvimento do espírito crítico, deve se configurar como uma referência para o reconhecimento, respeito, acolhimento, diálogo e convívio coma diversidade.

O que se pretende é educar para cidadania, considerando o potencial dos atores sociais do espaço escolar para promoção da cultura democrática que tenha como premissa o reconhecimento e respeito à diversidade sexual e à identidade de gênero.

\title{
3.4 Terceiro capítulo - A diversidade sexual na escola
}

Conforme os autores doo Caderno Brasil Sem Homofobia(2004, p.23):

\begin{abstract}
Aproposta é contribuir, com reflexões e sugestões de atividades, para elaboração de planos de ação voltados à construção de PPPs (Projetos Políticos - Pedagógicos) que respondam a necessidade de enfretamento da homofobia na escola. A ideia central nessa parte é de mobilizar a comunidade escolar para que a diversidade seja contemplada com as devidas extensões e responsabilidade nos currículos e nas práticas escolares, enfrentando os desafios cotidianos relacionados à orientação sexual e à identidade de gênero de estudantes, professoras/es e toda comunidade escolar. Com esse objetivo, foram elaborados caminhos e pistas para uma escola sem homofobia, entrelaçados na sugestão de elaboração de Projetos Políticos - Pedagógicos para subsidiar um processo coletivo de sua construção, execução e avaliação. O PPP é um instrumento teórico metodológico que visa ajudar a enfrentar os problemas cotidianos da escola, como os relacionados à orientação sexual e a identidade de gênero.
\end{abstract}

A construção coletiva de um projeto político pedagógico (PPP), encerra umprocesso rico para o diálogo da instituição escolar com as questões sociais de toda ordem:

Ao construirmos os projetos de nossas escolas, planejamos o que temos intenção de fazer, de realizar". Lançamos-nos para adiante, com base no que temos, buscando o possível. Nessa perspectiva, o projeto político-pedagógico vai além de um simples argumentos de planos de ensino e de atividades diversas (VEIGA, 2013, p.12). 
O caderno contém anexo 1 que apresenta sugestões de atividades a serem desenvolvidas com cada bolesh(Boletim Escola Sem Homofobia). No anexo 2há orientações para trabalhar com audiovisuais (filmes, programas de televisão, internet), programas de rádio etc.

\subsection{Os boleshs}

É direcionado aos alunos, totalizando seis boleshs. Foi concebido com o propósito deque cada estudante tivesse o seu exemplar. Não possuem uma estrutura rígida, e cada número trabalha uma temáticarelacionada aos direitos da população LGBT (o que é ser mulher e o que é ser homem; orientação sexual; diversidade sexual; homofobia; direitos; relações familiares) .Apresenta ainda "texto de fundo, textos menores e disparadores de jogos", além de desenhos e cartuns que provocam reflexões.

Ao desenvolver as atividades planejadas e previstas no caderno e junto com as/os estudantes, a facilitadora ou o facilitador terá mais oportunidades de criar momentos de curiosidades epistemológicas, essencial para a formação do espírito crítico em adolescentes e jovens estudantes. (BRASIL, 2015).

\subsection{Os audiovisuais: Medo de que? Boneca na mochila e Torpedo}

Estes recursos didáticos audiovisuais possuem guias de discussão com sinopse, comentários e sugestões de atividades para aa (os)educadoras(es) trabalharem os assuntos com a comunidade escolar.Ressalta-se que "Medo de que?" e"Torpedo"são especialmente direcionados aos estudantes. Por sua vez, o material "Boneca na mochila"não deve ser utilizado apenas para a formação de educadoras/es, como também com mães, pais e familiares que compões/participam da comunidade escolar, e estudantes em sala de aula.

Boneca na mochila, ficção que faz provocações sobre o quanto as expectativas de gênero propagadas na sociedade influenciam a educação formal e informal de crianças, mediante situações que, se não aconteceram em alguma escola, com certeza já foram vivenciadas por famílias no mesmo contexto ou em outros. Ao longo do audiovisual, apresenta-se momentos que revelam quanto preconceito existe em relação às pessoas não heterossexuais. Baseado numa história verídica, mostra um motorista de taxi que conduz uma mulher aflita, chamada a comparecer à escola, onde seu filho estuda, apenas 
porque flagraram com uma boneca na mochila. No caminho, casualmente, o rádio do táxi está sintonizando um programa sobre homossexualidade que noticia o fato que se passa na escola onde estuda o menino em questão e promove um debate com especialistas em educação e em psicologia, sobre o assunto. Quanto à classificação indicativa, enfatiza a não recomendação a menores de 10 anos. (CADERNO BRASIL, SEM HOMOFOBIA, 2004)

"Medo de quê" trata-se de um desenho animado que favorece uma reflexão crítica sobre como as expectativas que a sociedade tem em relação ao gênero influenciam a vivencia de cada pessoa com seus desejos, mostrando o cotidiano de personagens comuns na vida real. $O$ formato desenho animado, sem falas, facilita sua exibição para pessoas de diferentes contextos culturais, independente do nível de alfabetização das/os espectadoras/es.Marcelo, o personagem principal, é um garoto que, como tantos outros, têm sonhos, desejos e planos. Sua mãe seu pai, seu amigo João e a comunidade onde vive mostram expectativas em relação a ele que não são diferentes das que a sociedade tem a respeito dos meninos. Porém nem sempre os desejos de Marcelo correspondem ao que as pessoas esperam dele. Mas quais são mesmo os desejos de Marcelo? Essa questão gera medo, tanto em Marcelo quanto nas pessoas que os cercam.Medo de quê? Em geral as pessoas tem medo daquilo que não conhecem bem. Assim, muitas vezes alimentam preconceitos que se manifestam nas mais variadas formas de discriminação. A homofobia é uma delas.Este desenho não foi recomendado pra menores de 12 anos. (CADERNO BRASIL, SEM HOMOFOBIA, 2004)

"Torpedo" agrega três histórias cujo contexto é o ambiente escolar: Torpedo, Encontrando Bianca e Probabilidade. É uma animação com fotos, que apresentam a historia do inicio do namoro entre duas garotas estudantes na mesma escola: Ana Paula e Vanessa. Ana Paula estava na sala de informática quando deparou com toda a turma vendo na internet fotos dela e de Vanessa numa festa, que haviam sido divulgadas por alguém. A partir daí,as duas se questionam sobre como as pessoas irão reagir a isso e sobre que atitude devem tomar. Após algumas especulações, decidem se encontrar no pátio na hora do intervalo. Lá assertivamente, assumem sua relação afetiva num abraço carinhoso assistido por todas/os. (CADERNO BRASIL, SEM HOMOFOBIA, 2004). 
Encontrando Bianca, é uma narrativa ficcional em primeira pessoa, num tom confessional, como num diário íntimo, José Ricardo/Bianca relata a descoberta e a busca de sua identidade de travesti. Narrada em tempo presente, possibilita acompanhar a trajetória de Bianca e os dilemas de sua convivência dentro do ambiente escolar, tendo em vista seu desejo de se aproximar e se identificar com o universo das garotas. Detalha seu primeiro dia na escola com as unhas pintadas; a dificuldade de ser chamada pelo nome (Bianca) com o qual se identifica; os problemas por não conseguir utilizar, sem constrangimentos, tanto o banheiro feminino quanto o masculino; as ameaças e agressões de um lado e os poucos apoios de outro. (CADERNO BRASIL, SEM HOMOFOBIA, 2004)

Em Probabilidade, o narrador conta a história de Leonardo, Carla, Mateus e Rafael. Leonardo namora Carla e entristece porquesua família mudará para outra cidade. Na nova escola, Leonardo é acolhido por Mateus, que se torna um grande amigo. Mas ele só compreende porque faziam comentários homofóbicos a respeito dele e de Mateus quando este lhe diz ser gay. Certo dia Mateus convida Leonardo para a festa de despedida do primo, Rafael, que está de mudança. Durante a festa, Leonardo conversa com Rafael e, após a despedida, se vê pensando sobre a atração sexual que sentiu pelo novo amigo que partia. Inicialmente sentiu-se confuso, porque também se sentia atraído por mulheres, mas ficou aliviado quando começou a aceitar sua bissexualidade. Classificação indicativa: livre. (CADERNO BRASIL, SEM HOMOFOBIA, 2004).

\section{Considerações finais}

A violência e a discriminação contra LGBTs é visível e sobre o Brasil pesa a estatística de estar entre os países que mais matam homoafetivos no mundo. O Projeto Brasil Sem Homofobia apresentou propostas pedagógicasque fomentassem a reflexão acerca do respeito e inclusão; por ser a escola um espaço por excelência de promoção de cidadania.

No que tange às políticas públicas, enfatiza-se a contribuição de Sousa (2015) que permite afirmar a existência dos obstáculos consideráveis quando se trata de ações e programas direcionados à população LGBT, que geralmente são dotados de menor força normativa, quando comparados a leis. 
É possível afirmar, tendo em vista a (não)receptividade obtida pelo material na sociedade, a necessidade de discussão e exploração dos aspectos envolvidos na afetividade/sexualidade tendo com fator fundante a pluralidade de ideias e o respeito à singularidade humana. Faz-se prementea participação democrática na promoção da cidadania LGBT, de vez que a uma das consequências mais cruéis do preconceito e da discriminação é culpabilizar as pessoas por serem quem são.

\section{Referências}

BRANDÃO, Paula de Freitas ; SANTANA, Teresa . O "kit gay": na saúde e na educação um kit de polêmicasRevista Eletrônica de Ciências Sociais, n.18, set. 2011. Disponível em: http://www.cchla.ufpb.br/caos/n18. Acesso em: 10 nov. 2018

BRASIL. Constituição Constituição da República Federativa do Brasil. Brasília, DF: Senado Federal: Centro Gráfico, 1988

BRASIL. MINISTÉRIO DA SAÚDE. CONSELHO NACIONAL DE COMBATE À DISCRIMINAÇÃO. Brasil sem Homofobia: Programa de Combate à Violência e à Discriminação contra GLTB e Promoção da Cidadania Homossexual. Brasília, DF, 2004. Disponível em <http://www.mj.gov.br/sedh/documentos/004_1_3>. Acesso em: 14 nov. 2018.

BRASIL. PRESIDÊNCIA DA REPÚBLICA. Estatuto da Criança e do Adolescente. Lei n. 8069, de 13 de julho de 1990. Brasília: Casa Civil/Subchefia para Assuntos Jurídicos, 1990. Disponível em: <http://www.planalto.gov.br/ccivil_03/LEIS/ L8069.htm>.

CADERNO ESCOLA SEM HOMOFOBIA. Ação Educativa. Disponível em: http://www.acaoeducativa.org.br/fdh/wp-content/uploads/2015/11/kit-gayescola-sem-homofobia-mec1.pdf. Acesso em: 08 nov. 2018

MORIN, Edgar. Os sete saberes necessários à educação do futuro. São Paulo/Brasília: Cortez/Unesco, 2001.

VEIGA, IIma Passos Alencastro. Projeto Político Pedagógico na Escola. São Paulo: Papirus, 2013

SOUSA, Camila Cristina de Castro. POLÍTICAS PÚBLICAS PARA

POPULAÇÃO LGBT NO BRASIL: do estado de coisas ao problema político. VII Jornada Internacional de Políticas Públicas. Disponível em: http://www.joinpp.ufma.br/jornadas/joinpp2015/pdfs. Acesso em: 16 nov. 2018

VIANNA, Claudia P. e RAMIRES, Lula. "A eloquência do silêncio: gênero e diversidade sexual nos conceitos de família veiculados por livros didáticos". Revista Psicologia Política, n. 8, 2008. 